\title{
Hedef Pazar Seçimi için Hibrit BWM-ARAS Karar Verme Modeli
}

\author{
Ahmet Çalık
}

\section{Özet}

Hedef pazarların sistematik olarak değerlendirilmesi ve seçilmesi bir firmanın uluslararasılaşması aşamasında başarı veya başarısızlığın ana belirleyicisi olabilmektedir. Herhangi bir pazarın değerlendirilmesini firmanın pazarlama karması (ürün, fiyat, dağıtım ve tanıtım), çevresel değişkenler, pazar payı, potansiyel karlılık ve hatta firmanın stratejik önemi gibi faktörler etkileyebilmektedir. Çok Kriterli Karar Verme (ÇKKV), önceden belirlenmiş alternatifler arasından en uygun olanı birçok kriter açısından değerlendirerek seçmeyi sağlayan bir kavramdır. Bu nedenle, hedef pazar seçimi firmalar için en önemli konulardan birisidir ve ÇKKV yöntemleri kullanılarak değerlendirilebilir. Bu çalışmada firmaların hedef pazar analizinde kullanabileceği entegre bir ÇKKV modeli önerilmiştir. Bu entegre model en iyi en kötü yöntem (BWM) ve The Additive Ratio Assessment (ARAS) yöntemlerine dayanmaktadır. Değerlendirme kriterlerin belirlenmesinde genel bir durum tespiti yapabilmek için PEST (Political, Economic, Socio-cultural, Technological) faktörlerinden yararlanılmış, BWM, kriterlerin önceliklendirilmesi aşamasında kullanılmış ve en uygun hedef pazar ARAS yöntemi ile belirlenmiştir. Önerilen modelin uygulaması, akademisyenler ve uygulayıcıların görülerinden hareketle bölgesel hedef pazar seçim kararı için gerçekleştirilmiştir. Çalışmanın sonuçlarına göre, karar vericilerin yeni bir hedef pazar seçimi konusunda ekonomik faktörlere daha fazla önem verdikleri tespit edilmiştir.
Anahtar Kelimeler

ARAS

BWM

Hedef Pazar Seçimi

Makale Hakkında

Geliş Tarihi: 12.11.2019

Kabul Tarihi: 02.09.2020

Doi: 10.18026/cbayarsos.646115

\section{A Hybrid BWM-ARAS Decision Making Model for Target Market Selection}

\begin{abstract}
Systematic evaluation and selection of target markets can be the main determinant of success or failure in the stage of internationalization of a firm. The evaluation of any market may be influenced by the firm's marketing mix (product, price, distribution and promotion), environmental variables, market share, potential profitability, and even the strategic importance of the firm. Multi-Criteria Decision Making (MCDM) is a concept that enables to select the most suitable alternatives from the predetermined alternatives in terms of many criteria. Therefore, target market selection is one of the most important issues for firms and can be evaluated using MCDM methods. In this study, an integrated MCDM model that firms can use in target market analysis is proposed. This integrated model is based on BWM and ARAS methods. PEST (Political, Economic, Socio-cultural, Technological) factors are utilized in order to make a general assessment in the identification of the evaluation criteria, the Best Worst Method (BWM) is used during the prioritization of the criteria and the most appropriate target market is determined by ARAS method. Implementation of the proposed model is based on the opinion of academicians and practitioners for the decision of regional target market selection. According to the results of the study, it was found that decisionmakers attach more importance to economic factors in the selection of a new target market.
\end{abstract}

Keywords

ARAS

BWM

Target Market Selection

About Article

Received: 12.11 .2019

Accepted: 02.09.2020

Doi: 10.18026/cbayarsos.646115

a İletişim Yazar1: ahmetcalik51@gmail.com

b Dr. Öğr. Üyesi, KTO Karatay Üniversitesi İ̈BF, ORCID No: 0000-0002-6796-0052 


\section{Giriş}

Günümüz küreselleşen dünyasında işletmeler arasındaki rekabetin gün geçtikçe artması işletmelerin kar marjlarını yükseltmesi için yeni pazarlara açılmasını zorunlu kılmıştır. Pazarlar tüketicilerin istek ve ihtiyaçlarına cevap veren yerler olduğu için insan ihtiyaçlarına en uygun yerlerin belirlenmesi yöneticiler için stratejik bir karar olarak karşımıza çıkmaktadır. Doğru pazar seçiminde yapılan hatalar, firmaların gelecekteki başarısı üzerinde uzun vadede olumsuz sonuçlar doğurabilmektedir (Malhotra, Sivakumar, \& Zhu, 2009).

Uluslararası pazarlara açılmak isteyen işletmeler için hangi pazarların ürün ve hizmetleri için daha uygun olduğu, uluslararası pazarlama politikaları ve hedefleriyle ilgilidir (Dickson \& Ginter, 1987). İlgilenilen ürünlerin dünyadaki pazar hacmi, karlılık potansiyeli, ürünün en büyük alıcıları ve rekabetin durumu gibi birçok kriter en iyi olan pazar veya pazarların tespitini zorlaştırmaktadır (Shipley, Johnson, Pointer, \& Yankov, 2013).

Hedef pazar seçimi işletmeler için stratejik bir karar olduğundan, karar vericilerin çelişkili kirterleri dikkate alarak birçok alternatif pazar arasından un uygun olanını belirlemesi karmaşık ve zaman alan bir süreç olarak tanımlanabilir (Aghdaie \& Alimardani, 2015). Hedef pazar seçimi için uygun pazarar tanımlanmalı, ardından kriterlerin önem düzeyi (ağırlıkları) belirlenmeli ve son olarak en iyi alternatif pazarı belirlemek için kriterler altında adaylar değerlendirilmelidir (Robertson \& Wood, 2001). Bu yapısıyla hedef pazar seçimi ÇKKV problemi olarak tanımlanabilir.

En uygun hedef pazar seçilirken, ihracat, ithalat ve ürün başına birim maliyet gibi nicel kriterlerle birlikte, birçok nitel kriterde dikkate alınmalıdır. Hedef pazar seçimi için, her kriter kesin olarak nicel bir biçimde değerlendirilemediği için uzmanların görüşleri de karar verme sürecinde yer almalıdır. Şirketlerin seçim problemleri için çeşitli ÇKKV yöntemleri önerilmiştir. BWM ve ARAS literatürdeki çalışmalarda farklı alanlara uygulanmıştır. Bu çalışmanın orijinal yönü, hedef pazar seçimi için BWM ve ARAS yöntemlerini birlikte kullanan ilk çalışma olmasıdır. Bu iki yöntem seçilmiştir çünkü BWM yöntemi nispeten yeni bir yöntemdir ve Analitik Hiyerarşi Süreci (AHP) gibi kriterlerin ağırlıklarını belirlemek için kullanılabilir. Daha iyi tutarlılık, tutarlı karşılaştırmalar, daha yakın ağırlık oranı sağlayan minimum toplam sapma ve daha az sayıda karşılaştırma AHP'ye göre BWM yöntemin temel avantajlarıdır (Sadjadi \& Karimi, 2018).

$\mathrm{Bu}$ çalışma, uluslararası yeni bir pazara açılmak isteyen işletmeler için genel bir durum değerlendirmesi yapabilmek için hedef pazar seçiminin nasıl yapılması gerektiği sorusuna cevap aramakta ve ÇKKV araştırmalarına katkıda bulunmaktadır. Hedef pazar seçimi kararı genellikle dış ticaret departmanlarında alınırken, doğru ve etkili seçim kararı verebilmek için farklı karar vericilerin de görüşlerinin alınması gerekmektedir. Bu çalışmada, küresel pazara girmenin değerlendirilmesinde belirli bir ürün veya sektörel bir ayrım yapmak yerine işletmelerin dış çevre analizinde bir karar destek sistemi önerilmiştir.

Yukarıda verilen bilgiler ışığında bu çalışmanın hedefleri aşağıdaki gibi belirlenmiştir:

1. Hedef pazar seçiminde çevresel faktörleri belirlemek ve ÇKKV ile bir karar destek sistemi oluşturmak

2. Grup karar verme sonucunda kriterlerin ağırlı̆̆ını elde etmek

3. Çeşitli alternatif pazarlar arasından en uygun olanı bölgesel olarak belirleyebilmek 
Araştırma hedeflerini ulaşabilmek için öncelikle hedef pazar seçiminde etkin kriterler uzman görüşleri ile değerlendirilerek makro ölçekte değerlendirme yapabilmek amacıyla PEST faktörleri kullanılmış, belirlenen faktörlerin ağırlıklarının elde edilmesinde BWM yönteminden ve aday pazarların sıralanması aşamasında ise ARAS yönteminden faydalanılmıştır.

Bu çalışmanın geri kalan bölümleri aşağıdaki bölümlerden oluşturulmuştur: İkinci bölümde, hedef pazar seçimi için pazar seçimine etki eden faktörler ve ÇKKV yöntemlerini içeren bir literatür taraması gerçekleştirilmiştir. Üçüncü bölümde temel araştırma yöntemleri açıklanmıştır. Dördüncü bölümde, Türkiye'de yer alan bir mobilya üreticisi yeni hedef pazar seçiminde önerilen karar destek sistemi ile desteklenmiştir. Son olarak, altıncı bölüm sonuçları özetlemekte ve gelecekteki araştırmaların sonuçlarını ortaya koymaktadır.

\section{Literatür Araştırması}

Yıllar boyunca, hedef pazarın seçilmesini değerlendirmek için sayısız çalışma gerçekleştirilmiştir. Robertson ve Wood (2001) yöneticilerin ihracat pazarlarını seçerken çeşitli kriterlerin önemli olduğunu Amerika Birleşik Devletleri'nin kuzeybatısındaki 275 ihracatçı firmanın görüşlerini inceleyerek belirlemişlerdir. Yöneticilere göre 'rekabet' (piyasa potansiyeli boyutunda) ve ardından genel talep en önemli 'tüketim' en az önemli kriter olarak sıralanmıştır. Albadvi, Sharifi ve Qahri Saremi (2007) PROMETHEE yöntemi ile alternatif pazarların sıralanması ve en iyi hedef pazarın belirlenmesi için ÇKKV yaklaşımı tanıtmışlardır. Önerilen yaklaşım, İran'daki TV pazarındaki bir örnek olay incelemesiyle ele alınmış ve hedeflenen pazarın segment hacmi ve hedeflenen şirketin giderleri en önemli kriterler olarak elde edilmiştir. Slater, Hult ve Olson (2007) 20 farklı gelişmiş sanayide faaliyet gösteren ileri teknoloji üretim ve hizmet firmaları üzerinde yoğunlaşarak, karar vericilerin başarı olasılıklarını artırmak için uluslararası pazarlarda atmaları gereken adımlar konusunda bir çalışma gerçekleştirmişlerdir. Anket araştırması sonucunda, müşteri odaklılık ve performans arasında hiçbir ilişkinin bulunmaması ve erken çoğunluğu hedefleme ile performans arasında negatif bir ilişki olduğu sonucu ortaya çıkmıştır. Taaffe, Geunes ve Romeijn (2008) pazar seçimi, pazarlama çabası ve satın alma kararlarını ele almak için karı maksimize eden bir model geliştirmişlerdir. Önerilen model envanterle ilgili maliyetleri hesaba katmakta ve reklamın her pazarın talebinin olasılık dağılımı üzerindeki etkilerini dikkate almaktadır. Shavin, Sivakumar ve Zhu (2009) kültürel, idari, coğrafi ve ekonomik uzaklık çerçevesini kullanarak, farklı uzaklık faktörlerinin firmaların dış pazar edinme davranışları üzerindeki rolüne ampirik destek sağlamışlardır. Gelişmekte olan 18 ülkenin firmaları tarafından tamamlanan sınır ötesi satın almaları 1990 ve 2006 yılları arasında incelenmiş ve en küçük kareler ve ılımlı regresyon analizi kullanılarak hipotezler test edilmiştir. Kültürel ve coğrafi uzaklık faktörlerinin sınır ötesi satın alma sayıları üzerinde önemli, negatif bir etkisi varken, idari ve ekonomik mesafelerin önemli ve pozitif bir etkisi olduğunu bulmuşlardır. Sonuçlar, ülkelerin pazar potansiyelinin küreselleşmenin etkisiyle uzaklığın rolünü telafi ettiğini ve hatta bazen geçersiz kıldığını göstermektedir. Priya ve Venkates (2012) AHP ve istatistiksel modelleme teknikleriyle bütünleşik bir yaklaşımla pazar seçimi için bir model önermişlerdir. Modelde, ilk olarak karar kriterlerini ve ağırlıklarını belirlemek için temel bileşenler analizi ve çoklu regresyon analizi kullanılmıştır. Ardından, AHP ile kararlaştırılan kriterler karşısında pazar konumları önceliklendirilmiştir. Hindistan'da çelik ürünlerinin perakende satışına yönelik kırsal pazar giriş noktaları önerilen model ile belirlenmiştir. Kırsal perakendecilik en önemli kriter ikien kırsal refah, kırsal sosyal 
altyapı bu kriteri izlamektedir. Shipley vd. (2013) ürünlerin alternatif pazarlara girişinde karar verme sorununu ele almak için pazara girişin bulanık çekiciliği (FAME) modelini geliştirilmişlerdir. FAME modeli ile potansiyel pazarlara yönelik belirli ürünlerin sıralanabileceği bulanık kural tabanlı işlemler kullanılarak Bulgaristan'daki bir şaraphanenin iki ürünü için bir uygulama gerçekleştirilmiştir. Model sonucunda dört faktörün önemli olduğu bulnmuştur: (1) firmanın her bir pazardaki pazarlama karmasının uygunluğu; (2) her pazardaki kilit rakibinin pazarlama karmasının uygunluğu; (3) her bir pazardaki çevresel koşullar; ve (4) her pazarın firmaya stratejik önemi. Gianluca, Vignola, Facchinetti ve Mastroleo (2014) küçük bir firmanın risk yönünden uluslararası pazar seçim karar süreci yöntemini test etmişlerdir. Alternatif pazarlar, geniş bir değişkenler kümesiyle çok kriterli bir yaklaşımla değerlendirilmiş ve sıralamalar bulanık bir uzman sistemle elde edilmiştir. Aghdaie ve Alimardani (2015) AHP ve TOPSIS yöntemlerini içeren bir modelle hedef pazar seçimini ele almışlardır. Üç ana kriterin (segmentle ilgili, finansal ve ekonomik, teknolojik) ve alt kriterlerin yer aldığı yaklaşımda, dört segmentin sıralaması TOPSIS yöntemi ile belirlenmiştir. Mehrnoosh ve Shamshiri (2017) Walvoord'un hedef pazar seçim modelini uygulayarak inşaat hizmetlerinin hedef pazar sıralaması 14 kriteri dikkate alınarak belirlenmiştir. Ekonomik bilgi ve GSYİH en yüksek etkiye sahipken, din faktörü karar verme üzerinde en az etkiye sahip olarak bulunmuştur. Utama, Chan, Gao ve Zahoor (2018) inşaat işletmelerinin uluslararası genişlemesi için karar destek sistemi olarak tasarlanan literatür taramasını sunmuşlardır.

Mammadov (2012) Azerbaycan Cumhuriyeti Devlet Petrol Şirketi ACDPŞ'nin hedef pazar belirleme sürecini, şirket yöneticileri ile görüşme yaparak anazli etmiş ve üretiminin kapasitesinin yüksek olması, şirketin daha fazla gelir elde etme isteği, ulusal hükümetin desteği ve teşviki şirketin yeni pazarlara açılmasında önemli faktörler olarak elde edilmiştir. Başak (2016) Türkiye'de çamaşır deterjanı sektöründe faaliyet gösteren çok uluslu şirketler açısından hedef pazar seçimi ve marka konumlandırma konusunu şirket yöneticileri ile yapılan mülakatlar ile ele almıştır. Yıldız (2018) Türkiye iç hat havayolu yolcu pazarında pazar bölümlerini anket yöntemiyle araştırmış ve pazar bölümü modellerinin, sosyo-demografik değişkenler ile havayolu işletmesi tercih kriterlerine göre farklılık gösterdiği tespit edilmiştir. Özdemir (2019) yapay sinir ağ1 ile toplam kuruyemiş ve kurutulmuş meyve ihracat miktarlarını dikkate alarak hedef pazar seçimi üzerine bir tahminde bulunulmuştur. Mete (2015) uluslararasi ticaret merkezi ve pazara erişim veri tabanından elde edilen verileri kullanarak, Türkiye' de zeytinyağı ihracatı için hedef pazar olarak ABD belirlenmiştir. Söyler ve Yaraş (2016) traverten pazarı için AHP-TOPSIS entegrasyonu ile hangi ülkeye giriş kararının daha avantajlı olduğu belirlenmiştir. Dört ana kriter arasında ödeme riskinin ağırlığının en fazla, ulaşılabilirliğin ağırlığının en az olduğu bulunmuştur. Yavuz (2016) Hatay'da mobilya sektöründe faaliyet gösteren bir firmanın Türkiye' de yer alan iller için pazar seçimini PROMETHEE yöntemine dayalı olarak ele almıştır. Dokuz kriterin dikkate alındığı çalışmada ev satışları, evlilik sayısı ve nüfus büyüklüğü en önemli kriterler bulunmuş ve İstanbul en ideal pazar olarak tespit edilmiştir. Y1lmaz, Ozturk ve Burdurlu (2017) mobilya sektörü için Türkiye' den altı ilin pazar sıralaması, beş kriteri dikkate alarak AHP-VIKOR hibrit yöntemi ile ele alınmıştır. Satış verileri, ithalat-ihracat değerleri, evlilik sayısı, nüfus artış oranı ve gelir düzeyi kriterleri içersinde gelir düzeyi en önemli kriter olarak tespit edilmiştir. Ünal ve İpekçi Çetin (2019) nüfus, kişi başı GSMH, gübre tüketimi, gübre üretimi, gübre ticareti dengesi, iş yapma kolaylığı, ülkelere uzaklık ve lojistik performans kriterleri ile aday 10 ülke AHP-TOPSIS yöntemi ile değerlendirilerek en uygun hedef pazar belirlenmiştir. 
Araştırmamız kendisini önceki literatürden şu şekilde ayırmaktadır:

a. Genel olarak bildiğimiz kadarıyla, BWM-ARAS yönteminin hedef pazar seçiminde makro ölçekte çevresel faktörler ile gerçek dünyadaki uygulaması neredeyse seyrek ve hatta yoktur. Bununla birlikte, hedef pazar seçim problemini ÇKKV yöntemleri ile sektör bazında inceleyen modelleme çalışmaları bulunabilmektedir.

b. Araştırmacılar farklı hedef pazar seçim yaklaşımları önermiş olsalar da, birkaçı grup karar verme perspektifinden seçime odaklanmıştır.

c. Literatür taramasından elde edilen kriterler ve karar vericilerin görüşlerini de dikkate alarak hedef pazar seçimi için sektör veya ürün gözetmeksizin genel bir değerlendirme yapabilmek için kriterler PEST analizinden belirlenmiştir.

d. Alternatif pazarların sıralaması ise ülke ayrımı gözetmek yerine bölgesel değerlendirme yapılarak bulunmuştur.

Bu çalışmada, BWM (kriterleri sıralamak ve ağırlıkları bulmak için) ve ARAS yöntemi (belirlenen kriterleri baz alarak hedef pazarları sıralamak için) birleştiren yeni bir entegre ÇKKV modeli kullanılmıştır.

\section{Önerilen Model}

Bu bölüm, hedef pazar seçimi için üç aşamalı entegre bir model önermektedir. Bu üç aşamalı modelin kullanılmasının amacı, öncelikle hedef pazar seçiminde optimize edilmiş ağırlıkları elde etmek ve daha sonra örnek uygulama için belirlenen hedef pazarlar arasında optimize edilmiş (en iyi) pazarı bulmaktır. İlk aşama, hedef pazar değerlendirme kriterlerinin literatür taraması ve uzman görüşü temelinde tanımlanmasını içermektedir. İkinci aşama, BWM kullanılarak belirlenen kriterlerin ağırlıklarının önceliklendirilmesi ve hesaplanmasından oluşmakta ve üçüncü aşama, ARAS yöntemini kullanarak en iyi alternatifin seçilmesinden meydana gelmektedir.

$\mathrm{Bu}$ aşamaların her biri aşağıda tartışılmaktadır:

\section{Değerlendirme Kriterleri ve Alternatiflerin Belirlenmesi}

İlk aşamada, akademisyenler, ticaret odası yöneticileri ve sektörde en az beş yıllık deneyime sahip uzmanlar arasından beş uzman karar grubu oluşturmak üzere seçilmiştir. Uzmanların görüşleri ile hedef pazar seçimi için nihai kriterler PEST faktörleri dikkate alınarak belirlenmiştir. Ayrıca, değerlendirilecek alternatif pazarlar seçilmiştir.

\section{En İyi En Kötü Yöntemi}

Bu adımda, nihai değerlendirme kriterleri öznel görüşleri birleştirerek ağırlıklandırılmaktadır. Rezaei (2015) tarafından geliştirilen BWM kriter ağırlıklarını hesaplamak için kullanılmaktadır.BWM'e dayalı öznel görüşler için, beş uzman grubu ilk olarak 1-9 değerlendirme ölçeğini kullanarak tüm kriterlere dilsel puanlar vermektedir. Ardından, kriterler için değerlendirme matrisi toplanmış ve karşılaştırma matrisinin tutarlılığı kontrol edilmiştir. Tutarlılık oranı hesaplandıktan sonra, kriterler için öznel ağırlıklar BWM ile hesaplanmiştır.

BWM, en iyi kriteri (alternatif) diğer kriterlerle (alternatifler) ve diğer tüm kriterleri (alternatifler) en kötü kriterle (alternatif) karşılaştırmaya dayalı bir ÇKKV yöntemidir. BWM, aşağıda sunulan beş adımdan oluşmaktadır (Rezaei, 2015, 2016): 
Adım 1: Değerlendirmede kullanılacak karar verme kriterleri belirlenir.

Karar vermeyi etkileyen kriterler $\left(C_{1}, C_{2}, \cdots, C_{n}\right)$ uzman görüşleri ve literatür taraması ile belirlenebilmektedir.

Adım 2: Karar kriterleri arasından en iyi (en önemli, en çekici, en çok tercih edilen) ve en kötü (en az önemli, en az istenen) karar verici tarafından belirlenir.

Adım 3: En iyi kriterin tercihi diğer kriterlere göre belirlenir. En iyi kriterin diğer krterlerden kaç kat üstun olduğu 1 ile 9 arasında bir ölçek kullanılarak ifade edilir. Sonuçtaki vektör, en iyi-diğerleri vektörü olarak adlandırılır ve $a_{B j}=\left(a_{B 1}, a_{B 2}, \ldots, a_{B n}\right)$ şeklinde ifade edilir.

burada; $a_{B j}$ en iyi kriter $b^{\prime}$ nin $j$. kritere göre üstünlüğünü (tercihini) ifade etmekte ve bu durumda $a_{B B}=1$ olmaktadır.

Adım 4: Diğer tüm kriterlerin en kötü kritere göre üstünlükleri (tercihleri), 1-9 ölçeğini kullanarak karşılaştırılır. Sonuçta ortaya çıkan vektör diğerleri-en kötü vektörü olarak aşağıdaki gibi gösterilir.

$A_{W}=\left(a_{W 1}, a_{W 2}, \ldots, a_{W n}\right)^{T}$

burada; $a_{W j} j$. kriterin en kötü kriter $w^{\prime}$ ye göre üstünlügünü (tercihini) ifade etmekte ve bu durumda $a_{W W}=1$ olmaktadır.

Adım 5: Kriterlerin optimal ağırlıkları $\left(w_{1}^{*}, w_{2}^{*}, \ldots, w_{n}^{*}\right)$ hesaplanır. Optimal ağırlıklar; en iyi kriterin diğer kriterlerle oluşturduğu mutlak farklar ile diğer kriterlerin en kötü kriterle oluşturduğu mutlak farklardan yola çıkılarak $\left|\frac{w_{B}}{w_{j}}-a_{B j}\right|$ ve $\left|\frac{w_{j}}{w_{W}}-a_{W j}\right|, \forall j$ için minimize edilir. A ğırlıkların negatif olmaması ve toplam koşulu dikkate alındığında, eşitlik (1)'de verilen problem ortaya çıkmaktadır:

$\min \max _{j}\left\{\left|\frac{w_{B}}{w_{j}}-a_{B j}\right|,\left|\frac{w_{j}}{w_{W}}-a_{W j}\right|\right\}$

$\sum_{j} w_{j}=1$

$w_{j} \geq 0 \forall j$

Eşitlik (1) doğrusal hale eşitlik (2)'deki gibi çevrilebilir:

$\min \xi$

$\left|\frac{w_{B}}{w_{j}}-a_{B j}\right| \leq \xi$

$\left|\frac{w_{j}}{w_{W}}-a_{W j}\right| \leq \xi$

$\sum_{j} w_{j}=1$

$w_{j} \geq 0 \forall j$

Eşitlik (2)'nin çözülmesi ile kriter ağırlıkları ve $\xi$ elde edilir.

\section{ARAS Yöntemi}

The Additive Ratio Assessment (ARAS) yöntemi Zavadskas ve Turskis (2010) tarafından geliştirilen bir ÇKKV yöntemidir. ARAS yöntemine göre, bir alternatifin göreli verimliliğini belirlemekte kullanılan bir fayda fonksiyonu değeri, kriterlerin değerleri ve ağırlıkları ile 
orantılıdır. ARAS yöntemini kullanarak problem çözme süreci aşağıdaki adımlarla gerçekleştirilir (Zavadskas \& Turskis, 2010).

Adım 1: Karar matrisi oluşturulur ve her kriter için en uygun performans derecesini belirlenir. $m$ alternatif sayısını, $n$ ise kriter sayısını göstermek üzere $X$ karar matrisi:

$X=\left[\begin{array}{ccccc}x_{01} & \cdots & x_{0 j} & \cdots & x_{0 n} \\ \vdots & \ddots & \vdots & \ddots & \vdots \\ x_{i 1} & \cdots & x_{i j} & \cdots & x_{i n} \\ \vdots & \ddots & \vdots & \ddots & \vdots \\ x_{m 1} & \cdots & x_{m j} & \cdots & x_{m n}\end{array}\right] ; i=0,2, \ldots, m ; j=0,2, \ldots, n$

şeklinde gösterilebilir. Karar matrisinde $x_{i j} i$. alternatifin $j$. kriterde gösterdiği performans değerini; $x_{0 j}$ ise $j$. kriterin en uygun (optimal) değerini ifade etmektedir.

Adım 2: Göz önünde bulundurulan kriterlerin optimum performans değerini belirlenir.

Karar vericiler için eğer $j$ kriterinin optimum değeri tanımlanmıyorsa o zaman

$x_{0 j}=\max _{i} x_{i j}$ fayda (maksimizasyon) durumu için;

$x_{0 j}=\min _{i} x_{i j}$ maliyet (minimizasyon) durumu için;

Adım 3: Normalize edilmiş karar matrisi oluşturulur.

$\bar{X}$ normalize karar matrisi $\bar{x}_{i j}$ değerlerinden meydana gelmekte ve fayda ya da maliyet özelliklerine göre eşitlik (5) ve (6)'ya göre hesaplanmaktadır.

Fayda özelliğime sahip her kriter için:

$\bar{x}_{i j}=\frac{x_{i j}}{\sum_{i=0}^{m} x_{i j}}$

Maliyet özelliğime sahip her kriter iki aşamalı prosedür uygulanarak normalleştirilir:

$x_{i j}=\frac{1}{x_{i j}^{*}} ; \bar{x}_{i j}=\frac{x_{i j}^{*}}{\sum_{i=0}^{m} x_{i j}^{*}}$

Normalize değerler hesaplandıktan sonra elde edilen değerler matris formunda yazılarak $\bar{X}$ normalize karar matrisi elde eşitlik (7)'deki gibi edilir:

$\bar{X}=\left[\begin{array}{ccccc}\bar{x}_{01} & \cdots & \bar{x}_{0 j} & \cdots & \bar{x}_{0 n} \\ \vdots & \ddots & \vdots & \ddots & \vdots \\ \bar{x}_{i 1} & \cdots & \bar{x}_{i j} & \cdots & \bar{x}_{i n} \\ \vdots & \ddots & \vdots & \ddots & \vdots \\ \bar{x}_{m 1} & \cdots & \bar{x}_{m j} & \cdots & \bar{x}_{m n}\end{array}\right] ; i=0,2, \ldots, m ; j=0,2, \ldots, n$

Adım 4: Ağırlıklı normalize edilmiş karar matrisinin oluşturulur.

Tüm kriterlerin ağırlıklı normalleştirilmiş değerleri eşitlik (8) ile hesaplanabilir:

$\hat{X}_{i j}=\bar{x}_{i j} \cdot w_{j} ; i=0,2, \ldots, m$

burada, $w_{j} j$. kriterin ağırlık değerini temsil etmekte ve $\bar{x}_{i j} j$. kriterin normalize değerini göstermektedir. 


$$
\hat{X}=\left[\begin{array}{ccccc}
\hat{x}_{01} & \cdots & \hat{x}_{0 j} & \cdots & \hat{x}_{0 n} \\
\vdots & \ddots & \vdots & \ddots & \vdots \\
\hat{x}_{i 1} & \cdots & \hat{x}_{i j} & \cdots & \hat{x}_{i n} \\
\vdots & \ddots & \vdots & \ddots & \vdots \\
\hat{x}_{m 1} & \cdots & \hat{x}_{m j} & \cdots & \hat{x}_{m n}
\end{array}\right] ; i=0,2, \ldots, m ; j=0,2, \ldots, n
$$

Adım 5: Optimallik fonksiyon değerlerinin hesaplanır.

Her bir alternatifin optimallik fonksiyon değerleri eşitlik (10) ile belirlenir.

$S_{i}=\sum_{j=1}^{1} \hat{X}_{i j} ; i=0,2, \ldots, m$

burada $S_{i} i$. alternatifin optimal fonksiyon değerini ifade etmektedir.

Adım 6: Fayda derecesi belirlenir ve sıralama yapılır.

Her bir alternatifin fayda derecesi eşitlik (11) ile hesaplanır.

$K_{i}=\frac{s_{i}}{S_{0}} ; i=0,2, \ldots, m$

burada $S_{i}$ ve $S_{0}$ her bir kriter ve en iyi alternatifin optimallik fonksiyon değeridir. Hesaplanan değerler, öncelik sırasına bağlı olarak büyükten küçüğe sıralanır ve karar alternatifleri ile ilgili değerlendirme yapılır.

\section{Örnek Uygulama}

500 milyar dolarlık ihracat hedefine sahip olan ülkemizde, hedef pazarların doğru olarak belirlenebilmesi hem araştırmacılar hem de uygulayıcılar için önemli bir konudur.

Önerilen hibrit BWM ve ARAS yöntemlerinin uygulanabilirliğini gösterebilmek için karar grubu ile genel bir değerlendirme yapılmasına karar verilmiştir. Çünkü hedef pazar seçimi, sektörden sektöre, üründen ürüne ve işletmeden işletmeye farklılaşabilecek bir konudur. Çalışmamızda ülkelere spesifik olarak odaklanmak yerine makro ölçekte genel bir değerlendirme yani bölgesel bazda değerlendirmenin uzmanlarla görüşme sonunda daha doğru olduğuna karar verilmiştir. Bu nedenle, hedef pazarın seçimi aday beş bölge seçilmiştir: Orta Asya, Balkan, AB, MENA ve Doğu Avrupa. Hedef pazar seçimi karar alma grubu, bir profesör, bir ihracat uzmanı, bir rekabet uzmanı, bir ekonomist ve bir satın alma uzmanı olmak üzere beş karar verici $(\mathrm{KV})^{\prime}$ den oluşturulmuştur.

En uygun alternatif pazarın (yani bölgenin) değerlendirilmesinin ve seçiminin yapılacağ kriterler listesinin belirlenmesi, sonraki adımlar için çok önemlidir. Yatırımcıların hedef pazardaki kararlarını etkileyen kriterler literatür araştırması ve karar alma grubu görüşleri sonucunda PEST analizindeki temel faktörler üzerinden gerçekleştirilmiş olup, değerlendirmede kullanılana kriterler şunlardır: politik, ekonomik, sosyal ve teknolojik. Durum analizinde kullanılan temel yöntemlerden birisi olan PEST analizi, makro ölçekteki faktörlerin tespit edilerek ele alınan karar problemini etkileyebilecek olan dış faktörlerin neler olacağını saptamak amacıyla kullanılmaktadır. Ele alınan karar probleminin hiyerarşik yapısı Şekil 1'de sunulmuştur. 


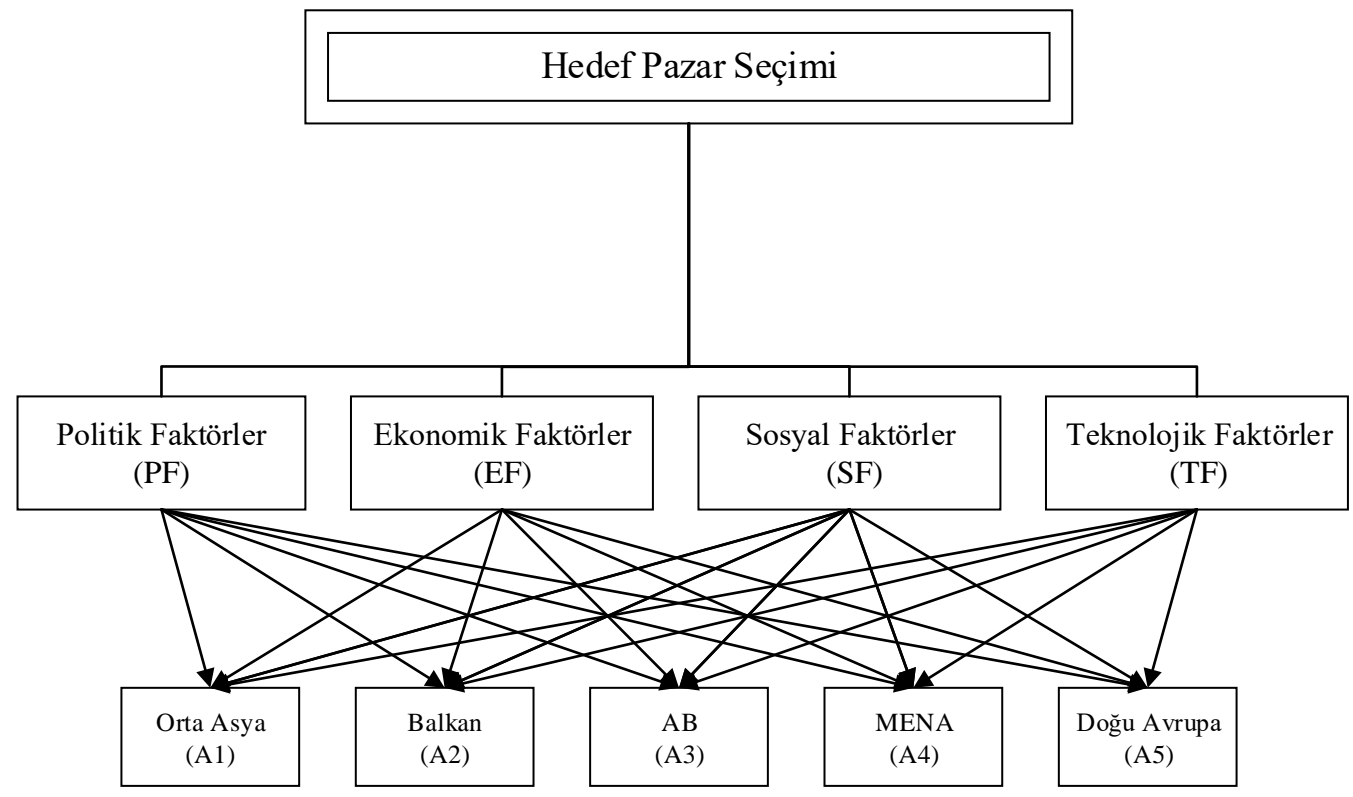

Şekil 1. Hiyerarşik yapı

\section{Kriter Ăğrlıklarının elde edilmesi}

Hedef pazar seçiminin kriterleri tamamlandıktan sonra, bu kriterlerin ağırlıkları çalışmanın 3.2 bölümünde gösterilen adımları kullanarak hesaplanmıştır. Tüm kriterler arasından, en iyi ve en kötü kriterler karşılıklı uzmanlar tarafından seçilmiş ve bundan sonra tüm diğer kriterlere göre en iyi kriter tercihi ve benzer şekilde en kötü kritere göre diğer kriterlerin tercihi 1-9 ölçeğinde uzmanlar tarafından belirlenmiştir. Dört ana kriter için tercih derecesi Tablo 1'de gösterilmektedir.

Tablo 1. Hedef Pazar seçiminin kriterlerinin karşılaştırılması

\begin{tabular}{lllllllllll}
\hline & \multicolumn{3}{c}{ Kriterler } & \multicolumn{7}{c}{ Kriterler } \\
Uzmanlar & En iyi & PF & EF & SF & TF & En kötü & PF & EF & SF & TF \\
\hline 1 & EF & 3 & 1 & 2 & 2 & SF & 2 & 4 & 1 & 3 \\
2 & PF & 1 & 2 & 2 & 4 & TF & 6 & 4 & 3 & 1 \\
3 & EF & 2 & 1 & 9 & 8 & SF & 7 & 8 & 1 & 3 \\
4 & EF & 3 & 1 & 5 & 7 & TF & 5 & 8 & 4 & 1 \\
5 & PF & 1 & 2 & 8 & 6 & SF & 8 & 5 & 1 & 3 \\
\hline
\end{tabular}

Tüm kriterler için tercih dereceleri aldıktan sonra, kriterlerin optimize edilmiş ağırlıkları, eşitlikler (1) ve (2) kullanılarak elde edilmiş, kriterler için optimize edilmiş ağırlıklar ve tutarlılık değeri Tablo 2'de gösterilmiştir. 
Tablo 2. Kriterlerin optimal ağırlıkları

\begin{tabular}{lllllc}
\hline Uzmanlar & PF & EF & SF & TF & $\xi$ \\
\hline 1 & 0.182 & 0.409 & 0.136 & 0.273 & 0.136 \\
2 & 0.417 & 0.250 & 0.250 & 0.083 & 0.083 \\
3 & 0.318 & 0.545 & 0.057 & 0.080 & 0.091 \\
4 & 0.229 & 0.569 & 0.138 & 0.064 & 0.119 \\
5 & 0.536 & 0.304 & 0.058 & 0.101 & 0.072 \\
\hline Ortalama & 0.287 & 0.443 & 0.145 & 0.125 &
\end{tabular}

\section{Alternatiflerin Stralanması}

Tüm kriterlerin ağırlıkları ve sıralamaları belirlendikten sonra, bir sonraki adım ARAS yöntemini kullanarak alternatifleri bu ağırlıkların temelinde sıralamaktır. Uzmanların hedef pazarları 1-9 arasında belirlenen derecelendirme ölçeğini kullanarak, belirlenen kriterlere göre alternatifleri ayrı ayrı değerlendirmeleri istenmiştir. Tüm uzmanların değerlendirmeleri Tablo 3'de gösterilmiştir.

Tablo 3. Uzmanlara göre alternatif pazarların değerlendirmeleri

\begin{tabular}{lllll}
\hline & PF & EF & SF & TF \\
\hline Orta Asya & $5,9,8,6,5$ & $5,5,8,6,5$ & $4,7,6,7,5$ & $3,3,8,6,4$ \\
Balkan & $3,7,8,8,4$ & $2,7,6,7,6$ & $3,8,6,8,6$ & $2,6,5,7,7$ \\
AB & $9,7,9,9,8$ & $9,9,9,9,9$ & $8,9,9,6,8$ & $9,9,9,9,9$ \\
MENA & $2,2,3,5,2$ & $3,3,9,5,4$ & $3,4,8,5,4$ & $2,3,3,5,3$ \\
Doğu Avrupa & $3,4,5,7,4$ & $4,5,6,8,7$ & $3,7,6,4,7$ & $4,5,5,8,4$ \\
\hline
\end{tabular}

Her uzmandan bireysel değerlendirmeler aldıktan sonra, bir sonraki adımda aritmetik ortalama yöntemi kullanılarak alternatifler için ortalama puanlar hesap edilmiştir (Tablo 4). eşitlik (5) ve (6) kullanılarak normalize edilmiş karar matrisi oluşturulmuştur (Tablo 5). Ardından, ağırlıklandırılmış normalize karar matrisi eşitlik (8) ile hesaplanmış ve Tablo 6'da gösterilmiştir. Eşitlik (10) ve (11) kullanılarak optimal fonksiyon değeri ve fayda derecesi hesap edilerek Tablo 7' deki sonuçlar elde edilmiştir.

Tablo 4. Alternatif pazarların ortalama değerlendirmeleri ile elde edilen karar matrisi

\begin{tabular}{lllll}
\hline & PF & EF & SF & TF \\
\hline Orta Asya & 6.6 & 5.8 & 5.8 & 4.8 \\
Balkan & 6 & 5.6 & 6.2 & 5.4 \\
AB & 8.4 & 9 & 8 & 9 \\
MENA & 2.8 & 4.8 & 4.8 & 3.2 \\
Doğu Avrupa & 4.6 & 6 & 5.4 & 5.2 \\
\hline
\end{tabular}


Tablo 5. Normalize edilmiş karar matrisi

\begin{tabular}{lllll}
\hline & PF & EF & SF & TF \\
\hline Optimal değerler & 0.228 & 0.224 & 0.209 & 0.246 \\
Orta Asya & 0.179 & 0.144 & 0.152 & 0.131 \\
Balkan & 0.163 & 0.139 & 0.162 & 0.148 \\
AB & 0.228 & 0.224 & 0.209 & 0.246 \\
MENA & 0.076 & 0.119 & 0.126 & 0.087 \\
Doğu Avrupa & 0.125 & 0.149 & 0.141 & 0.142 \\
\hline
\end{tabular}

Tablo 6. Ağırlıklı normalize edilmiş karar matrisi

\begin{tabular}{lllll}
\hline & PF & EF & SF & TF \\
\hline Optimal değerler & 0.066 & 0.099 & 0.030 & 0.031 \\
Orta Asya & 0.051 & 0.064 & 0.022 & 0.016 \\
Balkan & 0.047 & 0.062 & 0.024 & 0.018 \\
AB & 0.066 & 0.099 & 0.030 & 0.031 \\
MENA & 0.022 & 0.053 & 0.018 & 0.011 \\
Doğu Avrupa & 0.036 & 0.066 & 0.020 & 0.018 \\
\hline
\end{tabular}

Tablo 7. Optimallik fonksiyon ve fayda değerleri

\begin{tabular}{lcc}
\hline & $S_{i}$ & $K_{i}$ \\
\hline Optimal değerler & 0.226 & \\
Orta Asya & 0.154 & 0.681 \\
Balkan & 0.150 & 0.666 \\
AB & 0.226 & 1.000 \\
MENA & 0.104 & 0.460 \\
Doğu Avrupa & 0.140 & 0.621 \\
\hline
\end{tabular}

Ele alınan alternatif pazarlar artan bir sırayla sıralanmışlar, $K_{i}$ değeri daha yüksek olan alternatifler daha yüksek bir önceliğe sahiptir ve en büyük değere sahip olan alternatif pazar $\mathrm{AB}$ bölgesidir. $\mathrm{Bu}$ çalışmada, $\mathrm{AB}$ bölgesi, alternatif pazarlar arasında hedef pazar değerlendirmesinde ilk aday olarak yer almıştır. Orta Asya ve Balkan bölgeleri ilk bölgenin ardından en çok tercih edilen bölgelerdir.

Bu bölümde, farklı koşulların alternatif pazarların sıralaması üzerindeki etkisini analiz etmek için bir duyarlılık analizi yapılmıştır. Farklı kriter ağırlıkları ile ilgili 11 senaryo incelenmiştir. Tablo 8, dikkate alınan senaryoların ayrıntılarını göstermektedir. ARAS yöntemi ile tedarikçilerin sıralanmasındaki sonuçlar bu tabloda vurgulanmıştır. Aday pazar A3 ve A4 alternatiflerinin sıralama sonuçları, kriterlerin ağırlıklarını değiştirdiğimizde ARAS 
yönteminde sabit kalmıştır. Politik faktörlerin ağırlığının fazla olduğu durumlarda A1 alternatifi en iyi ikinci aday olurken, teknolojik faktörlerin ağırlık kazandığ A2 alternatifi ön plana çımıştır. A2 alternatifi altı senaryoda en iyi ikinci hedef pazarken, A1 alternatifi dört senaryoda en iyi ikinci hedef pazar olmuştur.

Tablo 8. Farklı senaryolar için duyarlılık analizinin sonuçları

\begin{tabular}{lcl}
\hline Senaryolar & Karar kriterleri ve ağırlikları & $\begin{array}{c}\text { Alternatif } \\
\text { siralamalar1 }\end{array}$ \\
\hline Mevcut durum & $W_{P F}=0.287, W_{E F}=0.443, W_{S F}=0.145, W_{T F}=0.125$ & $\mathrm{~A} 3, \mathrm{~A} 1, \mathrm{~A} 2, \mathrm{~A} 5, \mathrm{~A} 4$ \\
Senaryo 1 & $W_{P F}=1, W_{E F}=0, W_{S F}=0, W_{T F}=0$ & $\mathrm{~A} 3, \mathrm{~A} 1, \mathrm{~A} 2, \mathrm{~A} 5, \mathrm{~A} 4$ \\
Senaryo 2 & $W_{P F}=0, W_{E F}=1, W_{S F}=0, W_{T F}=0$ & $\mathrm{~A} 3, \mathrm{~A} 5, \mathrm{~A} 1, \mathrm{~A} 2, \mathrm{~A} 4$ \\
Senaryo 3 & $W_{P F}=0, W_{E F}=0, W_{S F}=1, W_{T F}=0$ & $\mathrm{~A} 3, \mathrm{~A} 2, \mathrm{~A} 1, \mathrm{~A} 5, \mathrm{~A} 4$ \\
Senaryo 4 & $W_{P F}=0, W_{E F}=0, W_{S F}=0, W_{T F}=1$ & $\mathrm{~A} 3, \mathrm{~A} 2, \mathrm{~A} 5, \mathrm{~A} 1, \mathrm{~A} 4$ \\
Senaryo 5 & $W_{P F}=0.25, W_{E F}=0.25, W_{S F}=0.25, W_{T F}=0.25$ & $\mathrm{~A} 3, \mathrm{~A} 2, \mathrm{~A} 1, \mathrm{~A} 5, \mathrm{~A} 4$ \\
Senaryo 6 & $W_{P F}=0.5, W_{E F}=0.5, W_{S F}=0, W_{T F}=0$ & $\mathrm{~A} 3, \mathrm{~A} 1, \mathrm{~A} 2, \mathrm{~A} 5, \mathrm{~A} 4$ \\
Senaryo 7 & $W_{P F}=0.5, W_{E F}=0, W_{S F}=0.5, W_{T F}=0$ & $\mathrm{~A} 3, \mathrm{~A} 1, \mathrm{~A} 2, \mathrm{~A} 5, \mathrm{~A} 4$ \\
Senaryo 8 & $W_{P F}=0.5, W_{E F}=0, W_{S F}=0, W_{T F}=0.5$ & $\mathrm{~A} 3, \mathrm{~A} 2, \mathrm{~A} 1, \mathrm{~A} 5, \mathrm{~A} 4$ \\
Senaryo 9 & $W_{P F}=0, W_{E F}=0.5, W_{S F}=0.5, W_{T F}=0$ & $\mathrm{~A} 3, \mathrm{~A} 2, \mathrm{~A} 1, \mathrm{~A} 5, \mathrm{~A} 4$ \\
Senaryo 10 & $W_{P F}=0, W_{E F}=0.5, W_{S F}=0, W_{T F}=0.5$ & $\mathrm{~A} 3, \mathrm{~A} 5, \mathrm{~A} 2, \mathrm{~A} 1, \mathrm{~A} 4$ \\
Senaryo 11 & $W_{P F}=0, W_{E F}=0, W_{S F}=0.5, W_{T F}=0.5$ & $\mathrm{~A} 3, \mathrm{~A} 2, \mathrm{~A} 5, \mathrm{~A} 1, \mathrm{~A} 4$ \\
\hline
\end{tabular}

${ }^{*} W_{P F, E F, S F, T F}$ Faktörlerin ağırlıklarını, U1, .., U5 uzmanları ifade etmektedir

\section{Sonuçlar ve Çıkarımlar}

Günümüzde pazarlama stratejileri değişim geçirmekte ve pazarlama kararları bir işletmenin her bir unsurunu etkileyebilmektedir. Pazar seçimi sürecinin pazarlama planlarına dâhil edilmesi, karmaşık ve maliyetli süreçteki olumsuzlukların azaltılmasına yardımcı olabilmektedir. Hedef pazar, diğer birçok kararın kalbi olduğu için şirketin kritik bir kararı ve politik etkinliğidir. İstikrarlı büyümenin ihracata dayalı anlayış benimsendiği ülkemizde, hedef pazar seçimi dış ticaretteki önemli sorunlardan birisidir. Bu nedenle, ülkemizdeki işletmeler için hedef pazar seçiminde önemli faktörleri belirlemek ve önceliklendirmek için bu çalışmada üç aşamalı hibrit bir ÇKKV modeli önerilmiştir.

İlk olarak, literatür taraması sonucunda hedef pazar seçimi ile ilgili özellikler belirlenmiş, uzman görüşlerinin dikkate alınması ile dört ana kriter araştırmaya dahil edilmiş, ardından belirlenen kriterleri sıralamak için BWM kullanılmış ve son olarak ARAS yöntemi ile alternatif pazarlar değerlendirilmiştir. Hedef pazar seçim kriterlerinin önceliklendirilmesi ile, ekonomik faktörler ile politik faktörlerin en önemli kriterler olarak sıralandığ 1 belirlenmiştir.

Hedef pazarlarda mevcut olan kültürel, politik, ekonomik ve kurumsal farklılıklar (Johanson \& Vahlne, 1977), özellikle dış pazarlar konusunda daha az yetkinliğe sahip KOBİ'ler için hedef pazar seçimi kararı gerçekten karmaşık ve zorlaştırmaktadır. İşletmelerin ilgilendikleri pazara yönelik birçok kriter bulunmaktadır. ABD merkezli ihracatçlar için ekonomik, politik, kültürü 
konular ve pazar potansiyeli, altyap, ve en önemli pazar seçim kriterleri olarak tanımlanmıştır (Wood \& Robertson, 2000). Hedef ülkelerdeki politik ve ekonomik istikrarsızlık pazar seçim stratejisini dezavantajlı hale getirmektedir (Mammadov, 2012). Bu nedenle, uluslararası pazarlara girişte ekonomik ve politik faktörler pazarın doğru tanımlanaması için büyük önem taşımaktadır. Özellikle temel ekonomik göstergeler GSYİH, işsizlik, enflasyon ve kur dalgalanmaları (Doherty, 2009) gibi alt fakörlerinde pazar seçiminde önemli olduğu unutulmamalıdır. Ayrıca, ülkelere olan uzaklıkta hedef pazar seçimini doğrudan etkileyebilmektedi. Nitekim, Ünal ve İpekçi Çetin (2019) gübre üreticisinin hedef pazar yeri seçiminde en önemli kriter olarak ülkelere olan uzaklığ tespit etmiştir. Dünya üzerindeki en büyük siyasi ve ekonomik örgütlenmelerden birisi olan $A B$, dünya ekonomisinnin en güçlü aktörlerindendir. 2019 yılında Türkiye'nin ihracatının yaklaşık \%50'si AB ülkelerine ulaşmış, Orta Doğu ülkelerinin ihracatımızdaki payı \%19.3'e yükselmiştir (Türkiye İhracatçılar Meclisi, 2020). Son derece derin ve çeşitlendirilmiş bir pazar yapısına sahip olan $A B$, otomotiv, kimya ve makine sektöründeki ihracatlar ülkemize yeni pazar fırsatları sunmaktadır. Bu nedenle, araştırmamızda karar vericilerin tercihlerinde ilk sırada yer almıştır.

Bu çalışma çeşitli sınırlamalara sahiptir. Öncelikle çalışma Türkiye'de ihracat yapmak isteyen işletmelerin hedef pazarlara açılması bağlamında gerçekleştirilmiş ve alternatif pazarların özellikleri ülkeden ülkeye değişebilmektedir. Hedef pazar seçim kriterleri sadece PEST analizindeki ana faktörler dikkate alınarak değerlendirilmiş, alt faktörlere çalışmada yer verilmemiştir. Alternatif pazarlarda ise sadece bölgesel bazlı bir çalışma gerçekleştirilmiştir. Ayrıca, çalışma ÇKKV yöntemlerine dayandığından ve bu teknikler analiz için büyük örneklem büyüklüğü gerektirmediğinden, örneklem büyüklügü sorunu vardır. Ayrıca, bu çalışma için belirlenmiş kriterler muğlaklık ve belirsizliğe sahip olduğundan kriterleri değerlendirmede bulanık sayıları içeren yöntemler kullanarak daha iyi sonuçlar alınabilir.

\section{Kaynakça}

Aghdaie, M., \& Alimardani, M. (2015). Target market selection based on market segment evaluation: A multiple attribute decision making approach. International Journal of Operational Research (C. 24). https://doi.org/10.1504/IJOR.2015.072231

Albadvi, A., Sharifi, S. A., \& Qahri Saremi, H. (2007). Application of PROMETHEE" for Market Targeting: A Case Study on the TV Market in Iran. Scientia Iranica, 14(3), 221-229. http://scientiairanica.sharif.edu/article_2768.html

Başak, L. (2016). Türkiye'de Çamaşır Deterjanı Sektöründe Faaliyet Gösteren Çok Uluslu Şirketlerde Hedef Pazar Seçimi ve Marka Konumlandırma (Yüksek Lisans tezi, Nişantaşı Üniversitesi, İstanbul). Erişim adresi: http://tez2.yok.gov.tr/

Dickson, P. R., \& Ginter, J. L. (1987). Market Segmentation, Product Differentiation, and Marketing Strategy. Journal of Marketing, 51(2), 1-10. https://doi.org/10.2307/1251125

Doherty, A. M. (2009). Market and partner selection processes in international retail franchising. Journal of Business Research, 62(5), 528-534. https://doi.org/https://doi.org/10.1016/j.jbusres.2008.06.011

Gianluca, M., Vignola, M., Facchinetti, G., \& Mastroleo, G. (2014). International market selection for small firms: a fuzzy-based decision process. European Journal of Marketing, 48(11/12), 2198-2212. https://doi.org/10.1108/EJM-09-2012-0512 
Johanson, J., \& Vahlne, J.-E. (1977). The Internationalization Process of the Firm-A Model of Knowledge Development and Increasing Foreign Market Commitments. Journal of International Business Studies, 8(1), 23-32. https://doi.org/10.1057/palgrave.jibs.8490676

Mammadov, E. (2012). Uluslararasi Hedef Pazar Seçimi ve Uluslararasi Pazarlara Gìrişs Stratejileri: Azerbaycan Cumhuriyeti Devlet Petrol Şirketi Örneği (Yüksek Lisans tezi, Ankara Üniversitesi, Ankara). Erişim adresi: http://tez2.yok.gov.tr/

Malhotra, S., Sivakumar, K., \& Zhu, P. (2009). Distance factors and target market selection: the moderating effect of market potential. International Marketing Review, 26(6), 651-673. https://doi.org/10.1108/02651330911001332

Mehrnoosh, M., \& Shamshiri, F. (2017). Prioritizing Target Markets for the Export of Iran Construction Services. Iranian Economic Review, 21(3), 621-637. https://doi.org/10.22059/ier.2017.62943

Mete, M. (2015). The Importance of Target Market Selection for More Profitable Olive Oil Exports by Turkey: A Case Study. Gaziantep University Journal of Social Sciences, 14(24223), 371-386. https://doi.org/10.21547/jss.256773

Özdemir, O. (2019). İhracat Hedef Pazar Seçiminde Yapay Sinir A ̆̆g ile Öngörü (Yüksek Lisans tezi, Gebze Teknik Üniversitesi, Gebze). Erişim adresi: http://tez2.yok.gov.tr/

Priya, P., \& Venkatesh, A. (2012). Integration of Analytic Hierarchy Process with Regression Analysis to Identify Attractive Locations for Market Expansion. Journal of Multi-Criteria Decision Analysis, 19(3-4), 143-153. https://doi.org/10.1002/mcda.1471

Rezaei, J. (2015). Best-worst multi-criteria decision-making method. Omega, 53, 49-57. https://doi.org/10.1016/J.OMEGA.2014.11.009

Rezaei, J. (2016). Best-worst multi-criteria decision-making method: Some properties and a linear model. Omega, 64, 126-130. https://doi.org/10.1016/J.OMEGA.2015.12.001

Robertson, K. R., \& Wood, V. R. (2001). The relative importance of types of information in the foreign market selection process. International Business Review, 10(3), 363-379. https://doi.org/10.1016/S0969-5931(01)00021-X

Sadjadi, S., \& Karimi, M. (2018). Best-worst multi-criteria decision-making method: A robust approach. Decision Science Letters, 7, 323-340. https://doi.org/10.5267/j.dsl.2018.3.003

Shavin, M., Sivakumar, K., \& Zhu, P. C. (2009). Distance factors and target market selection: the moderating effect of market potential. International Marketing Review, 26(6), 651-673. https://doi.org/10.1108/02651330911001332

Shipley, M. F., Johnson, M., Pointer, L., \& Yankov, N. (2013). A fuzzy attractiveness of market entry (FAME) model for market selection decisions. Journal of the Operational Research Society, 64(4), 597-610. https://doi.org/10.1057/jors.2012.59

Slater, S. F., Hult, G. T. M., \& Olson, E. M. (2007). On the importance of matching strategic behavior and target market selection to business strategy in high-tech markets. Journal of the Academy of Marketing Science, 35(1), 5-17. https://doi.org/10.1007/s11747-006-0002-4

Söyler, H., \& Yaraş, E. (2016). Küresel Pazara Giriş Kararinin Bulanik Ahp Ve Bulanik Topsis Yaklaşimiyla Analizi. MANAS Sosyal Araştırmalar Dergisi, 5(4), 77-96. 
Taaffe, K., Geunes, J., \& Romeijn, H. E. (2008). Target market selection and marketing effort under uncertainty: The selective newsvendor. European Journal of Operational Research, 189(3), 987-1003. https://doi.org/10.1016/J.EJOR.2006.11.049

Türkiye İhracatçlar Meclisi. (2020). İhracat 2020 Raporu, Yeni Vizyon, Yeni Yol Haritası.

Utama, W. P., Chan, A. P. C., Gao, R., \& Zahoor, H. (2018). Making international expansion decision for construction enterprises with multiple criteria: a literature review approach. International Journal of Construction Management, 18(3), 221-231. https://doi.org/10.1080/15623599.2017.1315527

Ünal, Z., \& İpekçi Çetin, E. (2019). Gübre üreticisinin hedef pazar seçiminde bütünleşik AHPTOPSIS yöntemi. Mediterranean Agricultural Sciences, 32(3), 357-364. https://doi.org/10.29136/mediterranean.584120

Wood, V. R., \& Robertson, K. R. (2000). Evaluating international markets: The importance of information by industry, by country of destination, and by type of export transaction. International Marketing Review, 17(1), 34-55. https://doi.org/10.1108/02651330010314704

Yavuz, A. (2016). Coğrafi Pazar Seçiminde PROMETHEE ve Entropi Yöntemlerine Dayalı Çok Kriterli Bir Analiz Mobilya Sektöründe Bir Uygulama. Ni⿱ğde Üniversitesi İktisadi ve İdari Bilimler Fakültesi Dergisi, 9(2), 163-177.

Yıldız, A. (2018). Havayolu İşletmelerinde Pazar Bölümlendirme ve Müşteri Tercihleri Açısından Değerlendirilmesi. (Doktora tezi, Muğla Sıtkı Koçman Üniversitesi, Muğla). Erişim adresi: http://tez2.yok.gov.tr/

Yılmaz, K., Ozturk, Y., \& Burdurlu, E. (2017). Çok Ölçütlü Karar Verme Yaklaşımı İle Mobilya İşletmeleri İçin Hedef Pazar Seçimi. İleri Teknoloji Bilimleri Dergisi, 6(3), 744-756.

Zavadskas, E. K., \& Turskis, Z. (2010). A new additive ratio assessment (ARAS) method in multicriteria decision-making. Ukio Technologinis ir Ekonominis Vystymas, 16(2), 159-172. https://doi.org/10.3846/tede.2010.10 